experience of residential care, and that among the proprietors there was a strong representation of those with previous experience of selfemployment, often in property management and development or in the tourist trade. 74 per cent of the homes had a married couple as the joint owners, 43 per cent had some help from family members and nearly one half had no full-time staff. On the other hand virtually all homes employed part-time staff, with a mean complement of seven. The survey suggests that some 3,000 part-time staff are employed throughout Devon in private residential homes for the elderly population.

On the basis of evidence both about the high turnover of proprietors and which suggested that as many as one quarter only planned to remain in the business for a short time, and in the light of the homes' high dependence on fees paid by the Department of Health and Social Security, the authors conclude that the future of the private residential sector is by no means soundly based. They suggest that an underfunded public sector and a largely undirected and potentially unstable private sector do not provide a sound basis for this aspect of the care of the nation's elderly. The article is accompanied by six tables and five maps, reinforcing its principal value as a detailed local account of a rapidly developing sector of British residential care for elderly people.

\title{
Policy Responses in Australia
}

\section{Tony Warnes}

Graeme Hugo, Population aging in Australia : implications for social and economic policy. Papers of the East-West Population Institute (Honolulu, Hawaii 96848) No. 96, April 1986, 47 pp., 26 tables, 5 figures.

This paper arises from the research and teaching programme on the nature and policy implications of ageing in Australia at the School of Social Sciences of Flinders University. Although Australia's population is in transition between the youthful structure characteristic of developing countries and the aged structure characteristic of Europe, in recent years the rate of increase in the nation's elderly population has been steeper than in almost all other developed countries. Australia's I 980 os experience of immigration, fertility and mortality have resulted in an unprecedentedly rapid increase of not only the number of older Australians but also their proportion of the total population. Social security programmes for the aged in Australia were extended and improved dramatically in the late r 970 during a period of growth of the young and working population.

After briefly reviewing the recent demographic ageing of Australia's 
population and the likely trends over the next two decades, the paper examines the Australian social security system. This differs substantially from those of most developed countries, including the United States, in that it is noncontributory and that historically it has focused on the alleviation of poverty rather than the replacement of earnings. Liberalisation of the eligibility criteria for the retirement age pension has resulted in its original function being supplanted, to the extent that most elderly people regard the pension as a substitute for earnings and as a right earned by paying taxes during their working lives. Hugo argues that widened access to government-subsidised or funded pensions, to private superannuation and to a range of services available to the elderly population has influenced their behaviour. In particular, he demonstrates that the availability of pension income has contributed to the changing age of retirement, to innovations in migration behaviour and to the changing housing and living arrangements of the elderly population.

Given the imminent rapid growth of Australia's elderly population, the implications, not least in terms of public spending, are only just beginning to be grasped by policy makers. This new recognition has begun to produce pressure to change the social security provisions for the elderly group. Some of the proposed changes are reviewed in the paper and their possible effects upon the behaviour and well being of the Australian elderly population are briefly addressed. It is argued that the present system, while creating the impression of availability to all, in fact disproportionately favours the better-off segments of the older population. With the likelihood that current overall per capita support for the elderly is to be reduced in the face of rapid growth in their numbers, there is a danger that existing inequalities will be exacerbated, especially if a political strategy of universal, across-the-board cut-backs is preferred to reductions in eligibility for support and services.

The paper is supported by five figures and 26 useful and up-to-date tables covering such topics as economic activity rates by age, the absolute and relative value of retirement benefits and pensions, the spread of early retirement, migration characteristics among older people, housing conditions and projections of chronic ill health in the elderly population. There is a bibliography which includes a useful list of official statistics and surveys in Australia. 